Revista Iberoamericana, Vol. LXXIX, Núm. 243, Abril-Junio 2013, 501-522

\title{
PEREGRINACIONES ANTILLANAS: SOBRE EL SABER HEGEMÓNICO Y LA IDENTIDAD DIASPÓRICA ${ }^{1}$
}

\author{
POR \\ SiLVIO ToRres-SAILLANT \\ Syracuse University
}

\section{TRANSNACIONALIDAD POR ANTONOMASIA}

Pensar en cómo circulan el conocimiento y las prácticas culturales, especialmente la escritura artística y el discurso crítico, en el Caribe y en su diáspora, con énfasis en el pueblo dominicano, nos lleva irremediablemente a intentar valorar los discursos que han adquirido mayor prominencia en el estudio de la movilidad humana. Hablamos de aquellos esfuerzos académicos por justipreciar el desplazamiento y la dispersión de las comunidades de una sociedad a otra, entre lenguas, regiones, leyes y culturas, en fin, más allá del espacio nacional, étnico o tribal que la era moderna nos ha acostumbrado a ver como el ámbito natural de la gente. Durante las últimas décadas del siglo xx en varias disciplinas de las ciencias humanas entró en boga la perspectiva transnacionalista como esquema analítico idóneo para estudiar la movilidad de los seres humanos entre su tierra natal y determinado lugar de destino, a veces en sí mutable, que en circunstancias diversas los alberga. Muchos académicos coinciden en atribuir un papel decisivo en el despliegue del concepto de transnacionalismo a las antropólogas Nina Glick Schiller, Linda Basch y Cristina Blanc-Szanton, coautoras de influyentes trabajos dedicados a profundizar sobre la aplicabilidad de dicha noción (Glick Schiller, Basch y Blanc-Szanton 1-2; Gowricharn 7). Sin embargo, no ha faltado un número considerable de especialistas en temas sociales avocados a expresar salvedad en torno a distintas implicaciones de la visión transnacional formulada por las autoras en cuestión (Conway 263-65).

A mí me ha tocado entrar levemente en el debate motivado principalmente por la urgencia de llamar a la cordura en cuanto a la aplicabilidad del concepto a los movimientos poblacionales en el Caribe, una zona del planeta donde la relación simultánea con más de una sociedad ha caracterizado la experiencia humana desde el mero principio. Partiendo

1 Este trabajo se basa en el texto de una ponencia presentada en el memorable simposio Cartografiando los Senderos de la Cultura: La Circulación del Conocimiento y las Prácticas Culturales en el Caribe y en su Diáspora, organizado admirablemente por las colegas Anja Bandau y Martha Zapata Galindo, del Lateinamerika-Institut, Freie Universitat, Berlín, Alemania, 19 al 22 de julio de 2007. 
de la ilustración del caso de la población dominicana, he objetado la presunción con frecuencia discernible en la bibliografía sobre el tema de que el fenómeno poblacional estudiado data de una fecha reciente, digamos desde el surgimiento de la nueva fase de la llamaba economía global por ahí por la década del ochenta (Torres-Saillant, Diasporic Disquisitions 9-15; "Disquisiciones"). De igual manera, he disentido de la tendencia de varios promotores de la perspectiva transnacionalista a pronunciarse sobre la muerte del estado-nación y la descripción del momento actual como una etapa histórica en que las fronteras han perdido la capacidad de contener el movimiento de una humanidad que ha dicho basta y se ha desterritorializado, liberándose de la estrechez de la nación y afirmando su pertenencia en la anchura del planeta (Torres-Saillant, Intellectual History 93-103).

La presente ponderación no pretende negar la validez hermenéutica que pueda tener la perspectiva transnacional en las ciencias humanas contemporáneas para escudriñar en términos generales el despliegue de poblaciones a lo largo y ancho del planeta. Más bien, desea insistir en que, no obstante la fe que suscite el paradigma transnacional como recurso conceptual para hablar de la movilidad de la especie entre puntos cercanos y distantes del globo terráqueo donde su aplicación tenga sentido, vale la pena plantearse hasta qué punto lo tiene en ese pedazo del mundo llamado el Caribe. Es decir, podríamos preguntarnos en qué momento de la historia caribeña moderna dejó su población de sentir el impacto de la "transnacionalidad" igual en la esfera pública que en los recovecos privados de la cotidianidad. ¿Quién en un país del mundo antillano ${ }^{2}$ puede cenar en un restaurante o comprarse una enciclopedia sin, a la hora de expedir el pago, pensar en la tasa de cambio que da valor a la moneda nacional por relación a la moneda de países poderosos en la órbita euro-norteamericana? La persona antillana no ha tenido oportunidad de vivir, laborar, o morir exenta de contacto diario con la llamada sociedad global.

El Caribe que conocemos hoy arrancó con una dinámica social, económica y política que habría de sumergir a toda su población en un profundo mar de interrelaciones con otros suelos y otros segmentos de la especie humana. Arrancamos con la conquista y la colonización protagonizada por las hordas del Occidente Cristiano a partir de 1492, la despoblación genocida de la región, el surgimiento de una industria globalizadora llamada plantación que no sabía otra cosa que entrelazar a gentes, tierras y ventajas distintas, así como, para repoblar, la llegada de mano de obra importada fuera esclava desde un continente o cautiva provisional desde otros. Durante la colonia, los bienes que producía el Caribe iban a enriquecer las naciones europeas rectoras de la transacción colonial. Tras surgir el ímpetu independentista, los movimientos insurreccionales se caracterizaron

2 Como en otros textos de mi autoría, aquí "Antillas" o "mundo antillano" funge como sinónimo total de "Caribe" o "West Indies". Los tres vocablos nombran para mí toda la región, abarcando tanto los territorios insulares como los continentales.

ISSN 0034-9631 (Impreso) 
por la colaboración intra-regional, como diría José Martí, prestándose las armas e intercambiándose los libertadores. Para el presente pos- y quizás anti-revolucionario que vivimos, las sociedades caribeñas han llegado a padecer un grado de dependencia económica, política e ideológica tal que el liderazgo local ya ni siquiera intenta imaginar soluciones a los problemas de la región que no vengan avaladas o prescritas por las élites dirigentes de los Estados Unidos o países europeos. La ruta a seguir en procura de opciones de desarrollo para el Caribe, pues, requieren recomendación de allende los mares y las industrias que proporcionan a las sociedades de la región su principal fuente de ingresos - turismo, zonas francas y remesas- vinculan la vida diaria de los pueblos antillanos de manera inextricable con tierras y gentes extranjeras. Lo "transnacional" es, pues, intrínseco a la experiencia histórica de los caribeños. De ahí que nadie se alarme ante el hecho de que hoy la cerveza "local" de Curazao venga elaborada y embotellada desde Ámsterdam, que Francia represente a Martinica ante la Asociación de Estados Caribeños o que de niños mis amiguitos y yo poseyéramos nociones de geopolítica. Es decir, aun viviendo en un Estado independiente llamado la República Dominicana, sabíamos que en cualquier contienda electoral venidera entre el desvergonzado Joaquín Balaguer y el honesto Juan Bosch, llevaba la de perder Bosch porque, como le oíamos decir a los mayores, "los americanos no lo quieren".

\section{SobRE LA IDENTIDAD DIASPÓRICA}

Ofrezco todo lo anterior como un corpus de detalles digno de considerarse para sustentar la observación de que las dinámicas que se desprenden de la relación con otras gentes y otras tierras forman parte orgánica e intrínseca de la experiencia histórica de los pueblos que habitan el mundo antillano. Propongo, por lo tanto, que un esquema analítico fundamentado en la "transnacionalidad" podrá arrojar luz sobre zonas de la humanidad donde dicho fenómeno provenga de desarrollos recientes pero no en lugares donde el mismo ocurra como sine qua non. Valerse, pues, de los recursos conceptuales que ofrece el transnacionalismo para explicar la movilidad de los caribeños, equivaldría a invocar el agua para explicar la vida de los peces o el aire la de las aves. Quizás encontremos un mayor caudal explicativo en el estudio de la identidad diaspórica para acercarnos a un aspecto de la movilidad caribeña que a mi parecer requiere mayor atención de la que se le ha consagrado. Podría considerarse a la persona antillana como homo migrans por excelencia. La observación del gran novelista y pensador barbadense George Lamming viene a colación cuando apunta a la textura "transnacional" del seno familiar en el Caribe, señalando, por ejemplo, que en Barbados a veces el fenómeno impide que un funeral se realice hasta por una semana después de la muerte del occiso por estimarse "incompleto el cortejo fúnebre hasta tanto no lleguen los dolientes de Jamaica, Trinidad, Guyana, Toronto, Birmingham, Brooklyn” (32). El sociólogo Ruben S. Gowricharn, quien hace

\footnotetext{
Revista Iberoamericana, Vol. LXXIX, Núm. 243, Abril-Junio 2013, 501-522 ISSN 0034-9631 (Impreso) ISSN 2154-4794 (Electrónico)
} 
ajustes a la perspectiva transnacionalista con miras a facilitar su aplicación al Caribe, enfatiza que el desplazamiento de esta población entre naciones no se circunscribe a una dirección. La emigración y la inmigración, ambas con perfiles diversos, caracterizan el mapa de la movilidad antillana. A la migración del Sur al Norte, es decir, desde el Caribe hacia las metrópolis de las potencias europeas y los Estados Unidos, hay que añadir la migración intra-regional, así como la diversidad de causas que motivan el flujo de personas hacia otras fronteras aparte de la razón laboral, tales como relaciones maritales, reunión familiar, la violencia y los regímenes dictatoriales (Gowricharn 8).

También cabe destacar que, además de enviar poblaciones a otras latitudes, el Caribe contemporáneo igual ha sabido recibir contingentes humanos cuantiosos de otras zonas del planeta, incluyendo el Medio Oriente, la India, China, Indonesia y varias partes de África. Así, lejos de limitarse al mapa demográfico conformado por los grupos étnicos dominantes en los tiempos de la conquista y la larga colonización de la región, el mundo antillano cuenta hoy con una amplia gama de poblaciones ancestralmente diferenciadas. Ellas son el producto de la movilidad previa y posterior al período de la Independencia: comunidades de origen africano, europeo, judío, asiático, indígena y de Oceanía. Tampoco hay que desestimar el detalle de que una décima parte de la migración caribeña se mueve hacia otros puntos de destino dentro de la misma región. Haití, República Dominicana, Guyana y Jamaica encabezan dicha movilidad en el alto número de migrantes que envían hacia otras sociedades antillanas y las Bahamas, las Islas Vírgenes y las Islas Turcos y Caico llevan la delantera en el alto número de inmigrantes que reciben (Fernández-Alfaro y Pascua 71). A la región tampoco le ha faltado su porción de la más maléfica expresión de la movilidad, la que corresponde al tráfico humano para su uso en la prostitución y otras variantes de la explotación sexual, el trabajo forzado, la servidumbre doméstica, las redes de vendedores ambulantes o de limosneros, el servicio militar forzado y hasta la extracción de órganos (Garret y Mahoney 149).

Para los fines de esta ponderación, podemos concentrar el enfoque en la migración que sale del Caribe y encuentra su lugar de destino en las grandes ciudades de los países rectores en el orden mundial, sobre todo cuando la movilidad resulta en un asentamiento de inmigrantes que en la sociedad receptora construyen para sí una comunidad con sus rasgos característicos. Normalmente, allí podemos constatar, especialmente a partir de la segunda generación, el surgimiento de una colectividad vinculada ancestralmente al Caribe, exhibiendo el distintivo de una identidad palpablemente diaspórica. Se desprende de ese perfil la tesis que afirma que la diáspora difiere sustancialmente del exilio aunque la estrecha relación entre ambos tipos de itinerancia a veces haga de una la antesala de la otra (Torres-Saillant, "Diáspora"). Al exiliado lo define la separación de un terruño temporal o permanentemente perdido. Al ciudadano diaspórico, en cambio, lo caracteriza la mediación -ya política, ya existencial-entre el país que concretamente habita y una

Revista Iberoamericana, Vol. LXXIX, Núm. 243, Abril-Junio 2013, $501-522$
ISSN 0034-9631 (Impreso) 
tierra o ascendencia ancestral de la cual se sirve en la distancia. Mentalmente, el exiliado vive en una matria originaria que aspira a recuperar. Un evocador poema de Bertold Brecht lo retrata renuente a desempacar las valijas y desdeñoso de todo gesto de permanencia en la sociedad receptora, como estudiar la lengua local o cuidar un árbol (Brecht 301-302). De dicho retrato se deduce una cierta actitud mental marcada por el temor a traicionar el origen ancestral. Parecería como si la posibilidad del regreso al terruño añorado se nutriera de su desdén por el entorno habitado. Los ciudadanos diaspóricos no viven en el exterior ni carecen de un hogar. El espacio vivencial que habitan constituye $s u$ hogar aun cuando le reconozcan cierto grado de precariedad. Han echado las simientes de ese hogar en el lugar donde les ha tocado vivir no obstante la falta de solidez que presientan en el suelo que pisan. En gran medida, la base identitaria de la ciudadanía diaspórica hay que buscarla en esa dualidad: la conciencia del potencial movedizo del suelo que se pisa y la ausencia de un ideal hogar originario que proporciona el consuelo de una pertenencia sin conflicto.

\section{EMIGRACIÓN Y DIÁSPORA DOMINICANAS}

La experiencia de los dominicanos ilustra con tanta propiedad como cualquier otra la historia de movilidad de la población antillana. Además, resulta particularmente útil porque ofrece una trayectoria bastante clara de la dispersión segmentada que ha vivido ese pueblo, una dispersión que nos permite distinguir entre distintos tipos de alejamiento del lar nativo y la variedad de identidades que ellos engendran. Se puede comenzar estableciendo diferencias identitarias entre los emigrantes salidos de la tierra natal hasta finales de la colonia en el siglo XIX, esa movilidad cuyas raíces databan de los inicios de Santo Domingo en el siglo xvI, y la emigración masiva que irrumpió a principios de 1960 (Torres-Saillant, El retorno31-34). Las anteriores emigraciones, suscitadas por invasiones, desastres naturales y cambios de batuta en el poder colonial, consistían principalmente en gente acomodada, mayormente blanca y poseedora de altos grados de instrucción. A ese perfil social privilegiado se debe que la partida de aquellos protocompatriotas pasara a registrarse en la historiografía dominicana tradicional, desde Antonio Sánchez Valverde en el siglo XVIII a Jacinto Gimbernard en la década del 1970, como una gran pérdida para el desarrollo de la sociedad. El gran éxodo de la segunda mitad del siglo Xx, por el contrario, por tratarse principalmente de gente proveniente de las grandes masas populares, inspiraría todo tipo de estereotipos deshumanizantes y discursos desnormalizadores en la esfera pública, como lo ilustra el surgimiento del Dominican-yorky del Cadenú, tipos sociales estigmatizados concebidos para representar moral y socialmente en la iconografía nacional a los que se fueron.

Pero el meollo de esta distinción se afinca en que la emigración posterior, contraria a las generaciones de emigrados anteriores, produjo una diáspora, la cual, a su vez, creó

\footnotetext{
Revista Iberoamericana, Vol. LXXIX, Núm. 243, Abril-Junio 2013, 501-522 
una literatura que hoy forma parte del corpus nacional de los Estados Unidos. También suscitó una mirada descalificadora de la producción cultural de esos hijos de emigrantes cuyo talento y cuya cosmovisión, sospechosos de inautenticidad nacional, debía tomarse cum grano salis. Véase la colección de artículos de opinión periodística reunidos bajo el título de La dominicanidad de Julia Álvarez de la autoría de un comentarista de libros dominicanos llamado Giovanni Di Pietro, quien arremete contra lo que él denomina "una supuesta literatura de la diáspora" (124). Por limitarse a exteriorizar su rechazo a manera de rabiaca, desnudo de argumento o disquisición, el juicio de dicho autor no amerita consideración real. Actualmente docente en la Universidad de Puerto Rico, recinto de Carolina, y anteriormente adscrito a universidades de la República Dominicana, donde acuñó credenciales críticas profiriendo pareceres voluntariosos en los diarios y en las páginas del suplemento Cultura del Siglo, Di Pietro se ha caracterizado por la renuencia a substanciar sus asertos. Aun así, la suerte le ha sonreído al gozar del apoyo de amigos dominicanos como el apasionado crítico y a la sazón director del referido suplemento, Diógenes Céspedes, quien en las palabras de salutación al escueto volumen sobre Álvarez agradece "a Di Pietro el hecho de que como extranjero se conduela de la literatura dominicana” al dedicarle sus idiosincráticas columnas (Céspedes 9).

\section{SOBRE PEREGRINACIONES E IDENTIDADES}

El caso dominicano aporta un valioso caudal a la reflexión que nos convoca acerca de la circulación del conocimiento y las prácticas culturales en el Caribe y su diáspora si regresamos a la distinción, a la luz de un magnífico capítulo sobre Pedro Henríquez Ureña que incluye Arcadio Díaz Quiñones en su asaz enjundiosa obra Sobre los principios: los intelectuales caribeños y la tradición (2006), para explorar un prometedor espacio de medianería entre las emigraciones de ayer y el gran éxodo contemporáneo. La poeta Rhina P. Espaillat ha descrito como un elemento constante en el drama de la especie el desplazamiento hacia geografías distintas de su suelo originario: "Así lo han hecho todos los hijos de Adán y Eva, viajantes incansables, amigos del cambio, víctimas del cambio, exiliados siempre sea por la política, la pobreza, el clima, el prejuicio, o el simple deseo de conocer la otra orilla, el otro lado de la montaña" (91). Provocado por la fría madurez con que Espaillat acoge esa itinerancia de los humanos, yo he aprovechado parte de mis palabras de introducción a una selección de sus escritos publicados por la Secretaría de Estado de Cultura de la República Dominicana, para destacar la especial propiedad con la que su concepto parece aplicarse como imperativo histórico a la población dominicana. En ese sentido, he apuntado que desde los inicios de la República Dominicana como estado-nación,

nuestra gente se ha visto obligada a considerar el destierro como opción de posponer la muerte o ganarse la vida. El repúblico Manuel Jimenes, miembro de la Junta Gubernativa

\footnotetext{
Revista Iberoamericana, Vol. LXXIX, Núm. 243, Abril-Junio 2013, 501-522 ISSN 0034-9631 (Impreso) ISSN 2154-4794 (Electrónico)
} 
que consolidó la independencia de la naciente República Dominicana en el 1844, el primer vice presidente que tuvo el país, así como su segundo presidente electo, terminó sus días bajo el amparo de la República de Haití, donde, como ciudadano haitiano, obtuvo la protección y el bienestar material que le negara el país que había ayudado a fundar. El venerado y venerable Juan Pablo Duarte, sin duda el mayor arquitecto intelectual de la nación dominicana, debió pasarse los que debieron haber sido los mejores años de su vida exiliado en Venezuela, donde al final murió. Dentro del plano literario, baste mencionar el hecho de que los dominicanos que alcanzaron el más alto sitial en el cultivo de las letras a lo largo del siglo veinte por razones distintas realizaron la mayor parte de su obra adulta en playas extranjeras. A Pedro Henríquez Ureña lo vemos arribar a los Estados Unidos en el 1901 para años después pasar a Cuba, luego a México y finalmente terminar su vida en la Argentina. Asimismo, alejados de la tierra natal en circunstancias diferentes pero compartiendo la misma necesidad de escapar de la asfixia ideológica y social que reinaba en el país durante las tres duras décadas de la dictadura trujillista, Juan Bosch, Manuel del Cabral y Pedro Mir se albergaron respectivamente en Puerto Rico, Cuba y la Argentina durante sus años más productivos. Lejos de detenerse, el panorama de dispersión dominicana que arrancó con el nacimiento de la República se ha acrecentado con cada nueva generación que esta tierra antillana trae al mundo. ("Formalismo" 8-9)

Ver la recurrencia de la huida como un hilo que traspasa el tejido de la experiencia histórica del pueblo dominicano nos da la necesaria justificación para entrelazar las historias de itinerancia que aquí hemos esbozado, incrustando en una sola narrativa, aunque sin pretensión de inconsútil continuidad, las emigraciones anteriores que no produjeron diáspora y la contemporánea que sí la produjo. Valga señalar que habrá quienes no circunscriban el calificativo de diáspora a la emigración de la segunda mitad del siglo xx. Véase, por ejemplo, la publicación electrónica editada por José E. Marcano titulada Mi País, cuyo portal ofrece, en una sección titulada "La Diáspora Dominicana", precisamente a "la intelectualidad dominicana emigrante" correspondiente a las emigraciones del pasado que ya hemos referido. La sección reproduce información provista por Pedro Henríquez Ureña en su obra La cultura y las letras coloniales en Santo Domingo (1936) para componer las estampas biográficas de los personajes incluidos, recalcando la manera como estos emigrados fueron a enriquecer, directamente o a través de los logros de sus proles, la vida del saber y las instituciones académicas en los países a donde llegaron. Por allí desfilan el renombrado intelectual cubano Domingo del Monte y Aponte, hijo de padre dominicano y sobrino del historiador dominicano, también trasladado a Cuba, Antonio del Monte y Tejada. Igual aparece el gran poeta de la independencia cubana, José María Heredia y Heredia, el reputado "cantor del Niágara", al igual que el poeta franco-cubano, autor del célebre volumen de sonetos Les Trophées, José-Maria de Heredia y Girard, descendientes ambos de José Francisco Heredia y Heredia, quien había salido de Santo Domingo en 1795 a raíz del Tratado de

Revista Iberoamericana, Vol. LXXIX, Núm. 243,
ISSN 0034-9631 (Impreso) 
Basilea para destacarse luego como letrado al servicio del régimen colonial en Cuba, Venezuela y México.

En ese contexto, se cita con frecuencia en la bibliografía cultural dominicana el juicio del crítico cubano Manuel de la Cruz al caracterizar a "aquellos hijos de la vecina isla de Santo Domingo que al emigrar a nuestra patria en las postrimerías del siglo XVIII, dieron grandísimo impulso al desarrollo de la cultura, siendo para algunas comarcas, particularmente para el Camagüey y Oriente, verdaderos civilizadores" (Henríquez Ureña citado en Marcano). Aunque en menor escala que en Cuba, no dejó de sentirse la presencia de los emigrados de Santo Domingo en Venezuela, donde descollaron José María Rojas como economista y periodista, y Rafael María Baralt, eminente poeta, historiador y lexicógrafo. A Puerto Rico también llegaron los efectos benéficos de aquel éxodo intelectual. Véanse los vínculos ancestrales del gran pensador boricua Eugenio María de Hostos con Santo Domingo, así como los de la poeta Lola Rodríguez de Tió. Menos mencionados en la bibliografía dominicana es la estirpe dominicana del caborrojeño Ramón Emeterio Betances, tenido por el independentismo boricua como padre de la patria puertorriqueña, y del narrador y ensayista José Luis González, autor del memorable ensayo El país de cuatro pisos. Bien se podría decir que hasta la Francia, "madre de las artes" según el verso de Joachim Du Bellay, llegó a beneficiarse de aquella gran fuga de cerebros que acaeció en Santo Domingo para la época. Bastaría referirse a la presencia allí del autor de Les trophées, cuya hija, Marie Heredia o Madame Henri de Regnier, quien bajo el nom de plume Gérard d'Houville también descolló en las letras, convirtiéndose en 1918 en la primera mujer escritora en recibir el Grand Prix de Littérature de la Académie Française, y la del pintor Théodore Chassériau, nacido en 1819 en Samaná, de padre francés y madre criolla.

Al proceder, en la mayoría de los casos citados, del Santo Domingo colonial, los letrados emigrados aquí señalados no sufrieron gran desarraigo al moverse de un punto a otro dentro de la vasta soberanía que les proporcionaba el imperio. Podían de esa manera sin grandes angustias transferir sus saberes y pericias a otros rincones de su patria colonial. Esa ancha geografía española hasta la era de las independencias americanas abarcaba todo el hemisferio occidental, ese gran dominio que durante la segunda mitad del siglo Xvi en los incontables versos de su Elegías de varones ilustres de Indias se propuso evocar el colonizador y poeta Juan de Castellanos. Su compatriota Agustín de Zárate, a quien William Ospina señala como el primer comentarista de la obra de Castellanos, admiró en el poema precisamente el atino de rememorar la gran proeza de los conquistadores españoles y "haber tomado a su cargo declarar como y cuando, y por quien se comenzó a descubrir tanta anchura de mar como hay ansí norte sur, como leste hueste, desde el estrecho de Gibraltar hasta las provincias de tierra firme donde van a parar" (Ospina 369). La anchura de esa enorme patria colonial que forjaron con su espada y su codicia los "varones ilustres" brindaba a los súbditos del imperio un

Revista Iberoamericana, Vol. LXXIX, Núm. 243, Abril-Junio 2013, $501-522$
ISSN 0034-9631 (Impreso) 
vasto suelo donde echar las simientes de su identidad. Cuando había desplazamiento, normalmente se debía a la necesidad de preservar su condición social y su privilegio si se veían afectados por cambios radicales en el statu quo local. Hubo desplazamiento cuando llegó un nuevo orden colonial durante la cesión de Santo Domingo a Francia por virtud del Tratado de Basilea en el 1795, o cuando Toussaint Louverture, líder de la insurrección en la colonia francesa de Saint Domingue, unificó toda la isla, declarando abolida la esclavitud en 1801. También lo hubo cuando posteriormente, respondiendo al proyecto separatista de José Núñez de Cáceres en 1821, Jean Pierre Boyer, presidente de la República de Haití, unifica de nuevo la isla bajo la jurisdicción del Estado haitiano.

Se puede decir que a los desplazados durante la colonia les embargaba menos el sentimiento de exilio que a aquellos que se vieron forzados a abandonar su país después de desmantelarse la patria colonial y fragmentarse la vasta soberanía del imperio. Otro sería el sentimiento de pertenencia a partir de los movimientos independentistas que culminaron en la creación de repúblicas diferenciadas, delimitadas por sus respectivas fronteras nacionales y con geografías específicas que enmarcaban espacialmente los contornos de cada ciudadanía. Con el surgimiento de las identidades nacionales y sus respectivos confines territoriales dentro de lo que antes fuera la vasta patria del imperio, se acrecienta sustancialmente el sentimiento de exilio para aquellos que deben dejar su terruño natal. Se tiene poca información de letrados que dejaran la República Dominicana en la segunda mitad del siglo XIX excepto cuando se iban a ocupar puestos diplomáticos o se tornaban desafectos del régimen político imperante en ese momento. A esos se les encuentra principalmente involucrados en las campañas de conspiración política que les prometía viabilizar el regreso a su país. La actividad literaria o intelectual desligada del proselitismo partidista escasea entre ellos. Al despuntar el siglo xx, parecen diversificarse las razones que sacan del país a representantes de la comunidad letrada.

\section{Culturas Peregrinas}

Cuando Pedro Henríquez Ureña llega a Nueva York en 1901 viene con sus hermanos Fran y Max, acompañados todos por su padre Francisco Henríquez y Carvajal. Allí inicia sus estudios universitarios y se dedica a la escritura, sentando las bases de sus primeros libros, Ensayos críticos (1905), publicado en La Habana, y Horas de estudio (1910) publicado en París. Después de haber vivido en Cuba y México por una década, Pedro regresa a los Estados Unidos en 1914, específicamente a Washington, D. C., como corresponsal del periódico El Heraldo de Cuba. Desde esta ciudad capital mantiene su columna periodística hasta abril de 1915, cuando se traslada a Nueva York para unirse al equipo redactor de Las Novedades (Torres-Saillant; "Before the Diaspora" 262). Este periódico, en el que al principio aparecen relatos y prosa crítica de autores principalmente españoles contemporáneos tales como Leopoldo Alas “Clarín”, Emilia Pardo Bazán,

\footnotetext{
Revista Iberoamericana, Vol. LXXIX, Núm. 243, Abril-Junio 2013, 501-522 ISSN 0034-9631 (Impreso) ISSN 2154-4794 (Electrónico)
} 
Juan Valera y Emilio Castelar, lo fundó por ahí por el año 1875 o 1876 D. J. G. García, un periodista presumiblemente español, quien lo dirigió hasta el 1911. Después de aparecer bajo la dirección de G. Hermanos hasta junio de 1914, la publicación pasa a manos de comerciantes y letrados dominicanos quienes la sostienen hasta finales del 1915 (Caballer Dondarza 105-106). Una carta de Henríquez y Carvajal dirigida a su hijo Pedro para la época da cuenta de su encuentro en Nueva York con varios escritores dominicanos conocidos, tales como Tulio M. Cestero, el autor de la novela La sangre (1912), además de consultar al joven letrado acerca de la posibilidad de iniciar en la gran ciudad un proyecto de publicación de libros en español, lo que da indicio del fervor literario dominicano e hispano que el padre había visto en la ciudad. Camila, la hermana de Pedro, después de recibir una maestría en letras hispánicas de la Universidad de Minnesota en 1918, regresaría a ejercer en Cuba, para volver a los Estados Unidos en 1941 a unirse al personal docente de Vassar College en Poughkeepsie, Nueva York, hasta que 17 años después pasó a enseñar de nuevo en Cuba hasta el fin de su vida en 1973.

También se podría mencionar a otros escritores, sobre todo poetas y narradores, que hicieron vida literaria desde Nueva York durante las primeras décadas del siglo Xx. José M. Bernard, Fabio Fiallo y Manuel Celestino Cestero sobresalen entre ellos. Luego sigue la producción literaria del exilio anti-trujillista, desde la década del cuarenta hasta la caída de la dictadura en 1961. Aquí se destacan los narradores Ángel Rafael Lamarche y Andrés Requena así como Carmita Landestoy, autora de una obra de repudio contra el gobierno del dictador Rafael Leonidas Trujillo titulada Yo también acuso (1946), cuya factura de denuncia se trasluce en su título alusivo al precedente de Émile Zola. Tanto los escritores de las primeras décadas del siglo $\mathrm{xx}$, como los que florecieron fuera del país durante la llamada Era de Trujillo, vivieron destierros de distintos tipos y duración. Característicamente su imaginación literaria apenas llega a arraigarse en la sociedad habitada. Rara vez retrata la experiencia humana que los circunda en el nuevo hábitat. Los pocos textos que invocan el lugar de residencia, como la colección de relatos Los cuentos que Nueva York no sabe de Ángel Rafael Lamarche y la novela El amor en Nueva York, de Manuel Celestino Cestero, llevan la impronta del transeúnte impresionable a quien el escenario inmediato le provoca aflicción, admiración o espanto. Aparte de tales casos, la literatura de dichos emigrados refleja un cosmos concebido desde la experiencia nacional y percibido desde una mirada proveniente de la patria. Lo dominicano propiamente dicho sigue circunscrito a la geografía del país emisor.

Una cronología política parecida a la de los letrados recién citados quizás explique la posición atípica del escritor Alan Cambeira. Este autor ha dado a la estampa obras en inglés y en español sobre la experiencia histórica y la composición sociocultural del pueblo dominicano: La fobia antihaitiana en la cultura dominicana (1987), Quisqueya la Bella: The Dominican Republic in Historical and Cultural Perspective (1997) y ¿Quiénes son los dominicanos? Caleidoscopio turbulento (2002), además de una trilogía de novelas

Revista Iberoamericana, Vol. LXXIX, Núm. 243, Abril-Junio 2013, $501-522$
ISSN 0034-9631 (Impreso) 
cuyos personajes padecen y se sobreponen a los altibajos de las penurias de una vida en el ingenio azucarero: Azúcar: The Story of Sugar (2003), Azúcar's Sweet Hope: Her Story Continues (2004), y Tattered Paradise: Azúcar's Trilogy Ends (2007). Natural de Samaná, Cambeira inició su itinerancia en la década del cuarenta, partiendo con su familia primero a Barbados, alcanzando luego Nueva York, para radicarse posteriormente en Pennsylvania. Con más de cincuenta años de haber vivido en los Estados Unidos, donde se especializó en estudios latinoamericanos hasta obtener el doctorado e integrándose a la docencia universitaria en instituciones predominantemente afroamericanas, su propia negritud al parecer le resultó insuficiente para lograr la integración plena. En el 2005 optó por cristalizar el ideal del regreso al lar nativo. Vale notar que ninguno de los escritos literarios conocidos de Cambeira se refiere a la vida norteamericana. Cuando el personaje central del primer tomo de su trilogía, Azúcar, escapa de la desolación del desafortunado batey donde ha nacido, yéndose al exterior, su migración le lleva a Canadá, lo que acentúa la ausencia de los Estados Unidos en el cosmos imaginativo de la obra literaria de Cambeira. Esa disociación para con la sociedad donde aconteció su experiencia de inmigrante sin duda se correlaciona con la vigencia que tuvo en su conciencia la idea de Samaná, su suelo natal, como hogar recuperable aún después de cinco décadas de haberlo dejado. Quizás estemos ante la presencia de un caso en el que durante medio siglo de haber salido de su país de origen, en la visión del emigrado primó el sentimiento exílico, cerrándole el paso a la adopción de una identidad diaspórica.

\section{LA DIÁSPORA INEXORABLE}

Contrario a las generaciones de emigrados que salieron de la parte hispánica de la isla de Santo Domingo desde los días de la colonia hasta la primera mitad del siglo xx, sobre las cuales existe escasa bibliografía, el gran éxodo dominicano que irrumpió a partir de la década del sesenta, especialmente la porción mayor que se enrumbó hacia los Estados Unidos, ha recibido una atención considerable por parte de los académicos. Hará más de un década que la bibliotecóloga Sarah Aponte le dedicó todo un tomo a la bibliografía anotada de los estudios sobre la inmigración dominicana a los Estados Unidos desde 1970 a 1997. Huelga decir que, si fuese a publicar un similar tomo anotando la bibliografía suscitada por el tema hasta el presente, tendría que duplicar el espesor de su libro (véase Aponte). De ese movimiento poblacional proviene el gran conglomerado humano que se ha llegado a conocer como "la comunidad dominicana en los Estados Unidos". El gran éxodo de la segunda mitad del siglo xx dio como resultado también el advenimiento de una diáspora. La misma ha producido un corpus literario rico en sugerencias acerca de su forma particular de manejar el significado de su dominicanidad. En una mirada rápida a los textos más conocidos, queda claro de inmediato que la relación de los personajes con el suelo norteamericano corresponde a

\footnotetext{
Revista Iberoamericana, Vol. LXXIX, Núm. 243, Abril-Junio 2013, 501-522 
una perspectiva que podemos llamar diaspórica por venir desprovista de sentimiento de dislocación, despojándose de la mirada fuereña, no obstante reconocer distintos niveles de tensión causados por su etnicidad.

La lista de autores y obras es enorme si consideramos la parte del corpus literario en cuestión producida en español en los distintos géneros literarios, además de prosa historiográfica, de análisis social y de crítica cultural, publicada mayormente bajo el patrocinio de los autores mismos. Quienes han tenido el mayor impacto, debido a la difusión que han gozado sus obras gracias al respaldo editorial de firmas poderosas, son los autores anglófonos. Encabeza esta lista la prolífica poeta y novelista Julia Álvarez, quien nació en Nueva York en 1950 y pasó los primeros diez años de su niñez en la tierra de sus padres, donde recibió instrucción escolar en inglés e inició la socialización norteamericana que continuaría en escuelas privadas al regresar a Nueva York en 1960. How the Garcia Girls Lost Their Accents (1991) e In the Time of the Butterflies (1994), entre varias otras obras de ficción, ensayo, relatos infantiles y poesía, le han ganado fama internacional. El hecho de que Álvarez, descendiente de una familia acomodada, blanca y con altos niveles de instrucción, lo que presumiblemente le abría la opción de la asimilación total a la cultura dominante, haya decidido alimentar su imaginación con los recursos de la memoria ancestral, se explica por el surgimiento de la población dominicana como un enclave étnico en los Estados Unidos. De alguna manera su carrera marca el momento de transición hacia una etapa en que los individuos dominicanos vinculados en Estados Unidos a las letras, las artes y el saber pierden la opción de dejar su dominicanidad inexpresa.

Comparable a Álvarez en visibilidad, Junot Díaz, cuya colección de relatos Drown (1996) lo colocó en un alto sitial del mercado literario norteamericano, con repercusión internacional debido a varias traducciones que aparecieron poco después de la edición original, constituye también una excepción en el plano del género ya que la literatura de la diáspora dominicana de expresión inglesa se sostiene en los hombros de mujeres. Con el galardón del Premio Pulitzer que mereció su novela The Brief Wondrous Life of Oscar Wao (2007), Díaz alcanzó un grado de celebridad y una visibilidad internacional sin precedentes entre los escritores norteamericanos de origen hispano. Hay que mencionar también la novela Geographies of Home (1999) de Loida Maritza Pérez, escritora nacida en la República Dominicana en 1963 y criada en Brooklyn, New York, de donde saldría para radicarse en Arizona. Más recientemente, con su primera novela Erzulie's Skirt (2006), que narra la relación y la itinerancia de Miriam y Michaela desde los campos y barrios marginados de la República Dominicana hasta los Estados Unidos -vía Puerto Rico-, Ana-Maurine Lara, poeta y narradora dominicana criada en África Oriental y Mount Vernon, Nueva York, se aventura a evocar una historia de amor lésbico entrelazada con la búsqueda de los significantes que emanan de la memoria ancestral sumergida. Aunque publicada por una casa editora marginal, la novela de Lara ha suscitado entusiastas salutaciones.

\footnotetext{
Revista Iberoamericana, Vol. LXXIX, Núm. 243, Abril-Junio 2013, 501-522 ISSN 0034-9631 (Impreso) ISSN 2154-4794 (Electrónico)
} 
De las autoras que han logrado visibilidad en el mercado literario de los Estados Unidos, tres restantes exigen consideración. Angie Cruz, la autora de las novelas Soledad (2001) y Let It Rain Coffee (2005), ambas publicadas bajo el sello de Simon \& Schuster, nació en Washington Heights de padres dominicanos en 1972. A mi pregunta sobre el momento cuando decidió que los personajes de su primer libro serían dominicanos, ella sin pestañar responde: "yo jamás pensé que no lo serían", respuesta contundente que lamentablemente no recoge la versión impresa de la entrevista que la joven novelista me concedió en el Public Theater de Nueva York en abril de 2001 (Torres-Saillant, "Writing" 108-27). La poeta Rhina P. Espaillat, nacida en Santo Domingo en 1932 y criada en La Vega hasta 1939, cuando finalmente se radicó con sus padres en Nueva York, compite exitosamente en el mercado de la poesía anglófona norteamericana, añadiendo a sus credenciales líricas, premios y lauros por cada volumen de versos que publica. Por identificación con sus orígenes ha preservado el uso del español, inserta voluntariosamente un par de poemas en castellano en sus libros anglófonos y colabora con poetas dominicanos residentes en Lawrence, Massachusetts, que escriben en español como César Sánchez Beras y José Matos, algunos de cuyos poemas ella ha traducido diestramente al inglés. Pero ni a Cruz ni a Espaillat se les ocurriría pensar en la tierra ancestral como un lugar donde regresar a radicarse. Tampoco se le ocurriría a Nelly Rosario, la autora de Song of the Water Saints (2002), una novela publicada por la editorial Pantheon. Rosario se crió en Brooklyn, Nueva York, después de haber venido desde Santo Domingo en los brazos de su madre como una bebé de tres meses de edad. Aunque se sabe dominicana y esa conciencia ancestral le sirva para orientar su ubicación en el plano cultural, rechazando el binarismo lingüístico y racial de la sociedad norteamericana, también siente que sus ocasionales viajes de verano a Santo Domingo no constituyen un regreso al hogar (Rosario 156). En fin, ninguna de estas figuras literarias, a juzgar por el cosmos que evocan sus obras, exhibe una imaginación influenciada por las propiedades del exiliado. Evocan la cotidianidad de una experiencia dominicana dada en la sociedad habitada y que se nutre de la memoria o la conciencia del lugar de origen ancestral sin, necesariamente, precisar recuperarlo. Su dominicanidad viene a graduar una forma particular de pertenecer al espacio ciudadano de su hogar inescapablemente norteamericano.

\section{DE HEGEMONÍAS Y SABERES}

Para completar el examen de la dispersión caribeña y la circulación de saberes y prácticas culturales, hace falta añadir al recuento anterior una pequeña tipología de las relaciones de los emigrados con la sociedad de origen y el suelo habitado, ayudándonos a distinguir, por un lado, a los que logran echar raíces en el entorno inmediato sin desvincularse cognitivamente del tronco ancestral y, por el otro, a los que representan

\footnotetext{
Revista Iberoamericana, Vol. LXXIX, Núm. 243, Abril-Junio 2013, 501-522 
todas las demás variantes en la historia de nuestra itinerancia. Desde el siglo XVII hasta la Era de Trujillo hubo quienes llevaron sus saberes a otras playas. Hay quienes viven largas décadas fuera de la tierra de origen y nunca pueden superar la necesidad de regresar a ella, como se ilustra en el caso de Alan Cambeira. Puesto que haber nacido en la geografía de un país no le confiere a uno automáticamente una memoria ancestral vinculada a ese suelo, hay quienes sencillamente le restan significación. Ello se ilustra con el caso de la tenista profesional de origen español y cubano Mary Joe Fernández, quien nació en la República Dominicana el 19 de agosto de 1971, y quien se vio precisada de corregir a los periodistas dominicanos que enfatizaban demasiado su dominicanidad en base a su mero nacimiento en el país, lo cual para ella resultaba intrascendente. En ese sentido habrá que preguntarse hasta qué punto le importaba a la memorable estrella de Hollywood María Montez el saberse oriunda de Barahona, una ciudad abocada a memorializarla como baluarte nacional bautizando con su nombre el aeropuerto local. Las señas de la dominicanidad con las que una persona pueda salir del terruño natal pueden sencillamente desaparecer con el tiempo. Así parece haber acontecido con el músico Manny Albam y con el joyero Francis Rebajes.

Enmanuel Albam nació en Samaná el 24 de junio de 1922, de padres rusos que aparentemente esperaban en aquella ciudad la oportunidad para viajar a la ciudad de Nueva York, su destino final. El niño creció en Nueva York tomando clases de saxofón en la escuela secundaria, y dejando los estudios a la edad de 16 años para destacarse por su talento y debutar profesionalmente en 1940. Obtuvo muchos lauros en las distintas bandas en las que tuvo la oportunidad de tocar, además de iniciarse como arreglista. Después de servir en el ejército de los Estados Unidos durante la Segunda Guerra Mundial entre 1945 y 1946, reinició su carrera como músico profesional hasta 1950, cuando se concentró en el trabajo de arreglista y compositor. Llegó a componer para 1957 una versión en jazz de West Side Story que mucho impresionó a Leonard Bernstein, quien lo invito a escribir para la Filarmónica de Nueva York. Al momento de su muerte el 2 de octubre de 2001, en Croton, Nueva York, Albam había completado siete décadas de participación estelar en el campo de la música, llegando a colaborar con muchas de las grandes estrellas del jazz como Count Basie, Dizzy Gillespie y Stan Getz, además de incursionar notablemente en la enseñanza y co-fundar la BMI Jazz Composers Workshop con su colega Bob Brookmeyer (véase Kirchner). Las fuentes rastreadas hasta ahora no dan indicio de que Albam le atribuyera significado especial alguno a su nacimiento dominicano.

Por su parte, Rebajes, nacido el 6 de febrero del 1906 en Puerto Plata, de padres mallorquines, llegó en 1923 a Nueva York, donde se casó con una norteamericana blanca y alcanzó éxito económico al incursionar sagazmente en la industria de la joyería, llegando a hacerse propietario de una cadena de tiendas para principios de la década del cuarenta. En 1958, empresario afortunado, Rebajes vendió su factoría y sus

\footnotetext{
Revista Iberoamericana, Vol. LXXIX, Núm. 243, Abril-Junio 2013, 501-522 ISSN 0034-9631 (Impreso) ISSN 2154-4794 (Electrónico)
} 
diseños a su capataz y se trasladó a Torremolinos, España, donde se dedicó a cultivar sus intereses estéticos y esotéricos. Rebajes murió el 8 de junio de 1990 en Boston, Massachusetts. Seguramente debido a sus facciones raciales exentas de perceptible negrura, su cosmovisión individualista que afinaba bien con la sociedad de consumo que lo recibió y, su falta de conexión con una minoría étnica diferenciada, el puertoplateño encontró abierta la opción de asimilarse en una época en que reinaba en los Estados Unidos, una política cultural que postulaba la homogeneidad de la nación, desestimando cualquier autoafirmación identitaria referente a grupos distintos de la herencia inglesa tenida como común denominador de la población. Esa exitosa asimilación le permitió diluir el rastro de su dominicanidad, prácticamente borrando las huellas del anterior nexo con su natal Puerto Plata.

Los rumbos por los que la itinerancia puede llevar a personas vinculadas a la experiencia dominicana pueden variar hasta en el seno de una misma familia. Tal caso lo presentan Jesusa Alfau Galván de Solalinde y su hermano Felipe Alfau. Hermanos de padre y madre, eran hijos de Antonio Abad Alfau Baralt, influyente abogado y orador, y de Eugenia Galván Velázquez, hija de Manuel de Jesús Galván, el célebre autor de la novela Enriquillo, sin dudas la obra más conocida de la literatura dominicana. En las postrimerías del siglo xIX, según narra el erudito dominicano Franklin Gutiérrez, la pareja salió del país para radicarse en Vigo, Galicia, donde en 1895 vino al mundo la niña Jesusa. Aparte de unos años de su niñez transcurridos en Santo Domingo, pasó la mayor parte de su vida entre España, Estados Unidos y México. Autora precoz de una novela titulada Los débiles (1912), Jesusa residió en Nueva York de 1916 a 1920, trasladándose luego a Wisconsin, donde permaneció hasta 1937, mudándose luego a México, donde vivió hasta 1943, año de su muerte (Gutiérrez 41-42). Durante sus años en Nueva York escribió crónicas para Las Novedades y en Wisconsin se dedicó, al lado de su esposo español, el académico Antonio G. Solalinde, a la investigación erudita, sobre todo de la cultura medieval española.

El nombre de Jesusa Alfau figura como escritora nacional en las historias literarias dominicanas. La colega dominicana Daisy Cocco de Filippis, destacada literata con grandes aportes en la labor crítica y en la traducción, se ha hecho una elocuente abanderada del legado literario de Jesusa Alfau. Cocco de Filippis les señala a los críticos literarios de la República Dominicana varias imprecisiones al referirse a su novela Los débiles, la cual pocos de los que la mencionan parecen haber tenido en sus manos. Cocco de Filippis critica a quienes, incluyendo a quien suscribe, han repetido el lugar común de la existencia de una versión en inglés de la novela de Jesusa, una falsedad que ella demuestra, estableciendo que lo que hubo fue una segunda edición publicada por Prentice Hall en 1930 como texto de lectura para estudiantes de español, bajo el cuidado editorial del hispanista J. Horace Nunemaker, con prólogo y anotaciones del editor escritas en inglés. Cocco de Filippis señala, con pesar, la ausencia en esa

\footnotetext{
Revista Iberoamericana, Vol. LXXIX, Núm. 243, Abril-Junio 2013, 501-522 
edición de alguna referencia a la familia dominicana de la autora ni a su estadía en la tierra ancestral, falla que también le achaca a los editores de Las Novedades (Cocco de Filippis, "Prólogo" 9-10). Curiosamente, Jesusa tampoco hace ninguna referencia a su propio pasado dominicano en la selección de sus escritos que Cocco de Filippis edita bajo el título Como los crisantemos lila: Jesusa Alfau Galván de Solalinde, Obra escogida (2000). Ha de ser Cocco de Filippis misma quien, como editora, enfatice esa relación, aseverando en su prólogo que "Jesusa Alfau Galván de Solalinde merece que se le conozca por su propio mérito y que se le llame nuestra. Esto lo afirmo, no solo por su cuna dominicana sino también por su vida errante dispersa entre España, República Dominicana, los Estados Unidos y México; presagio elegante de lo que será la existencia de muchos dominicanos en este siglo" (9).

Sin embargo, no existe similar interés en reclamar la dominicanidad de Felipe Alfau, el hermano menor de Jesusa y quien vino a Nueva York igual que ella en 1916. También, escritor, Felipe escogió la lengua inglesa para expresarse artísticamente (Cocco de Filippis, Desde la diáspora 46-47). Locos: A Comedy of Gestures, su primera novela, editada en 1936, le ganó una reseña muy favorable de la novelista y crítica norteamericana Mary McCarthy publicada en The Nation. Narración innovadora formal y temáticamente, se anticipa a la obra de reconocidos renovadores del género novelístico. La acción de la trama discurre principalmente en Toledo y Madrid. Su obra no tuvo ningún éxito comercial y Alfau parece haberse alejado de la escena literaria neoyorquina, por lo que no se vuelve a saber de él hasta que Dalkey Archives Press reedita la novela en 1988. Este redescubrimiento conduce a la publicación de Chromos, novela suya que permanecía inédita desde la década del cuarenta hasta que salió publicada en 1990, llegando a competir por el American Book Award. Previo a Locos, Felipe había dado a la imprenta un libro de relatos para niños titulado Old Tales from Spain (1929). De escritura en castellano solo se le conoce el tomito La poesía cursi/Sentimental Songs (1992), unas 50 páginas de versos escritos entre 1923 y 1987, publicado en edición bilingüe con las traducciones al inglés hechas por Ilan Stavans. La obra de Alfau recibió mucha atención mediante reseñas, comentarios y entrevistas tras ser redescubierto su autor, a quien en 1993 la Review of Contemporary Fiction le dedicó toda una sección de 110 páginas en el número de Primavera (Vol. 13, No. 1) bajo la coordinación de Stavans. En la entrevista que le concede a Stavans en el hogar de retiro en Rego Park, Queens, Nueva York, donde viviría por diez años hasta su muerte en 1999, Alfau se revela franquista, monárquico y reaccionario al valorar la sociedad española. En los versos se expresa racista al retratar despectivamente a las minorías étnicas que en las últimas décadas habían ganado auge en la ciudad de Nueva York. Ni en las palabras de Alfau ni en las de sus comentaristas aparece mención alguna de sus orígenes dominicanos. Cuando en la novela Chromos se aboca a ponderar a algún grupo étnico diferenciado, son los españoles residentes en Nueva York quienes le encienden la imaginación literaria.

Revista Iberoamericana, Vol. LXXIX, Núm. 243, Abril-Junio 2013, $501-522$
ISSN 0034-9631 (Impreso) 


\section{CONCLUSIONES}

Entre las múltiples observaciones que se desprenden de la circulación del conocimiento y las prácticas culturales en el contexto de la compleja historia de itinerancia que ha vivido la población dominicana, se impone de manera sobresaliente el dinamismo de los lazos que vinculan a los emigrados con la tierra ancestral. Vista la desaparición del rastro autóctono en la gente acaudalada que emigró de Santo Domingo en la era colonial, se constata también la dilución de la memoria del terruño natal en personas como los Alfau, Albam, Rebajes, Mary Joe Fernández y falta saber hasta qué punto también María Montez. Con la generación de Carmita Landestoy, vemos registrado también a un grupo de emigrados que, habiendo perdido el hogar por razones de exclusión o persecución, permanecieron aferrados al ideal del regreso para cifrar esperanzas en su bienestar, lográranlo o no. Entender la perdurabilidad del ideal de regreso después de una educación extranjera y medio siglo de ausencia del lar nativo en el caso de Cambeira, requerirá una profundización biográfica mayor de la que esta ponderación general nos puede permitir. Permítaseme cerrar brindando una formulación paradigmática. Deseo ilustrar mi planteamiento con dos figuras dominicanas que emigraron a edades parecidas pero en circunstancias históricas distintas. Ambas realizaron sus estudios universitarios en los Estados Unidos y ambas se comprometieron con la tarea de promover los textos y cuerpos de conocimientos con los que se sentían comprometidas. Propongo que la identidad diaspórica de la una y la experiencia primordialmente exílica de la otra marcó radicalmente la forma en que cada una configuró los saberes que habrían de promover y diseminar.

A su llegada a Nueva York en 1962, en su temprana adolescencia, Daisy Cocco de Filippis tenía apenas unos tres años menos que Pedro Henríquez Ureña cuando le tocó a él entrar a la ciudad de los rascacielos en 1901. Seguramente esa leve diferencia de años sirvió para moldear la naturaleza de la experiencia inmigratoria de cada uno, pues él terminó la secundaria en Santo Domingo y pudo venir a iniciar su educación universitaria en la sociedad receptora, mientras que ella entró a la escuela neoyorquina en el noveno grado (primer teórico) sin conocimientos de la lengua operante en el aula, además de los retos de adaptación cognitiva, sicológica y cultural que de ahí se desprenden. Cocco de Filippis ha rememorado su fascinación con Great Expectations, la novela de Dickens que le tocó leer para la clase de inglés mientras intentaba dominar la lengua de instrucción, señalando el sentimiento de identificación que le produjo el personaje de Pip, cuya marginalidad con respecto al mundo que aspira a conquistar reverberaba en la suya (Desde la diáspora 12-13).

Henríquez Ureña, por el contrario, ya estaba embebido de su posición con respecto a la gran tradición de las letras hispánicas y del pensamiento occidental antes de salir de su país. Al sentirse comprometido con la defensa y la promoción de esa herencia

\footnotetext{
Revista Iberoamericana, Vol. LXXIX, Núm. 243, Abril-Junio 2013, 501-522 ISSN 0034-9631 (Impreso) ISSN 2154-4794 (Electrónico)
} 
artística e intelectual, ya de alguna manera sabía la misión que le tocaría avanzar. En los compendios que dedicaba a esbozar la historia de la cultura y las corrientes literarias de Hispanoamérica, nuestro preclaro humanista buscaba sobretodo narrar la inserción del saber iberoamericano en la gran tradición gracias al legado de sus figuras señeras: "Bello, Sarmiento, Montalvo, Martí, Darío, Rodó" (Díaz-Quiñones 246). Igual aspiración le movía al historiar el aporte de los dominicanos. De ahí su alta valoración de las letras coloniales en Santo Domingo, aquel momento en que la isla fue la "Atenas del Nuevo Mundo". Enfrentaba un problemita, sin embargo, pues esa tradición que amaba y de la que se sentía heredero no estaba exenta de veleidades: negrofobia y otros racismos, misoginia, elitismo cultural, imperialismo etnocentrista y eurocentrismo radical. El mismo Pedro llegó a padecer esas veleidades occidentales en carne propia, al ser negreado en México y exotizado en la Argentina. Su vasta producción erudita y su renombre internacional no fueron suficiente para hacerlo elegible, por ejemplo, para obtener una plaza universitaria en Buenos Aires en los veinte años que dedicó a la docencia y la investigación allí (Díaz-Quiñones 212). Pero Henríquez Ureña tuvo que tragarse el bochorno, como lo indica la correspondencia suya que cita Díaz Quiñones (206). No tragárselo implicaría tener que enfrentar la tradición que amaba, de alguna manera salirse de ella para echarle en cara su exclusionismo. Igual habría pasado si hubiese destacado en su crónica de la cultura caribeña las otras riquezas que no provenían de las naciones conquistadoras sino de las poblaciones negras e indias. Su promoción de los aportes dominicanos, pues, debía mediarse puesto que había que hablar de la herencia criolla como si careciera de la africanía y todas esas inconveniencias culturales que reñían con el ideal de la hispanidad y con la universalidad de los valores occidentales.

Cocco de Filippis, al contrario, ha practicado su labor de erudición en una suerte de contienda con la tradición, creando espacio para lo femenino cuando ha visto la historia literaria demasiado varonil. Ha exigido inclusión de lo dominicano cuando ha visto a los cronistas de las letras hispanoamericanas concentrándose demasiado en la producción literaria de sus grandes capitales. También ha traído a colación el tema racial o de clase cuando su ausencia le ha resultado demasiado estridente en los análisis de la escritura artística en su país de origen. Igualmente, ha preparado antologías de los textos escritos en español por dominicanos en los Estados Unidos cuando ni a los literatos de la tierra natal ni a los gurús que dominan la formación del canon literario de los latinos en los Estados Unidos se les ha ocurrido incluirlos. En fin, ha intervenido en el campo del saber respondiendo a la tradición, enmendándola, refutándola, para hacerla más inclusiva del talento, del conocimiento y las prácticas culturales del mayor número posible de creadores que merecen reconocimiento por su aporte.

Explicar la disparidad que aquí señalo entre la relación de Henríquez Ureña y Cocco de Filippis con la tradición, invocando la época en que al uno y al otro les tocó vivir o las ideologías influyentes que reinaban en la generación de cada uno, quizás satisfaga

\footnotetext{
Revista Iberoamericana, Vol. LXXIX, Núm. 243, Abril-Junio 2013, 501-522 ISSN 0034-9631 (Impreso) ISSN 2154-4794 (Electrónico)
} 
a algunos. A otros seguramente les siga produciendo curiosidad averiguar precisamente qué tenía una época que no lo tuviera la otra para, verídicamente, contextualizar las diferencias de visión entre los dos académicos. Yo no buscaría respuesta en la historia de la ideas sino en la historia intelectual, entendiendo la primera como un proceso en que unas ideas van progresivamente engendrando otras más avanzadas y la segunda como un proceso en el cual las cosas que pasan en el mundo, es decir, fuera de la página, tienen un impacto en lo que la gente piensa sobre el intelecto, la cultura y todo lo demás. Henríquez Ureña en los Estados Unidos fortaleció su compromiso con el hispanismo y con los valores de la cultura occidental. La formación académica que recibió le permitió acumular autoridad, dejarse sentir en la pugna erudita y ejercer su influyente magisterio a lo ancho del hemisferio. Cocco de Filippis, por el contrario, inició su carrera académica en Nueva York a principios de la década de 1980, cuando ya los dominicanos en los Estados Unidos constituían una minoría étnica diferenciada. De hecho, los dominicanos ya se habían convertido en blanco de la xenofobia de la prensa neoyorquina que se daba a la tarea de criminalizar y patologizar a la comunidad por los males sociales que afrontaba como las drogas, el alto índice de delincuencia, la deserción escolar y el hacinamiento.

Pero para la fecha los dominicanos no carecían de armas conceptuales para contrarrestar el estigma. Tenían a su haber el legado discursivo y la praxis del Movimiento por los Derechos Civiles que, bajo el liderazgo de la población afroamericana, ya había dado vigencia a la lucha por la inclusión. Esa lucha no sólo buscaba abrir o mejorar las oportunidades de empleo o educación para los grupos de extracción no europea, sino que también combatía la lógica cultural que les negaba a las minorías el derecho a su diferencia. Ya para la fecha cuando Cocco de Filippis se hizo académica, los dominicanos, en respuesta a la difamación, tenían una práctica de lucha y un discurso de autoafirmación. La historia de la injusticia social les había politizado su identidad. Ella encontró una dominicanidad ya politizada, su origen ya semánticamente cargado. No se trata aquí, pues, de darle a Cocco de Filippis superioridad moral sobre Henríquez Ureña. Él tuvo que lidiar con las circunstancias que le proveyó su propio contexto. Carente de una comunidad diaspórica con la cual identificarse estrechamente, de un sector social cuyos intereses pudiera compartir para protegerse de vejaciones, él tuvo a bien dedicar sus mejores esfuerzos a la defensa de la tradición que su entorno reconocía como lo mejor. A ella las circunstancias históricas le hicieron ver la necesidad de distanciarse de esa misma tradición para protegerse étnicamente. El contrapunteo entre las trayectorias intelectuales de Henríquez Ureña y Cocco de Filippis acentúa el dinamismo de la larga y escalonada historia de la itinerancia dominicana, la cual viene de siglos. Asimismo, plasma de manera muy concreta el drama de la circulación de conocimientos y prácticas culturales, circulación que para nuestras poblaciones caribeñas, condenadas con

\footnotetext{
Revista Iberoamericana, Vol. LXXIX, Núm. 243, Abril-Junio 2013, 501-522 
frecuencia a peregrinar senderos siempre marcados por la desigualdad, involucran una tensa relación entre los saberes hegemónicos y la sapiencia vernácula.

\section{OBRAS CITADAS}

Alfau, Felipe. Locos: A Comedy of Gestures. 1936. Elmwood Park, IL: Dalkey Archive Press, 1988.

Old Tales from Spain. Garden City, NY: Doubleday, Doran \& Co., 1929. Chromos. Elmwood Park, IL: Dalkey Archive Press, 1990.

La poesía cursi/Sentimental Songs. Elmwood Park, IL: Dalkey Archive Press, 1992.

e Ilan Stavans. Dossier sobre Felipe Alfau. Review of Contemporary Fiction 1 (1993).

Alfau de Solalinde, Jesusa. Los débiles. Nueva York: Prentice-Hall, 1930.

Álvarez, Julia. How the Garcia Girls Lost Their Accents. Chapel Hill, Algonquin Books of Chapel Hill, 1991.

In the Time of the Butterflies. Chapel Hill: Algonquin Books of Chapel Hill, 1994.

Aponte, Sarah. Dominican Migration to the United States, 1970-1997: An Annotated Bibliography. Dominican Research Monographs. Nueva York: The CUNY Dominican Studies Institute, 1999.

Brecht, Bertolt. “Thoughts on the Duration of Exile." Bertolt Brecht: Poems, 1913-1956. John Willet y Ralph Manheim, eds. Nueva York: Methuen, 1979.

Caballer Dondarza, Mercedes. La narrativa española en la prensa estadounidense: hallazgo, promoción, publicación y crítica (1875-1900). Madrid: Iberoamericana Vervuert, 2007.

Cambeira, Alan. La fobia antihaitiana en la cultura dominicana. Santo Domingo: 1987. ¿Quiénes son los dominicanos? Caleidoscopio turbulento. La identidad nacional de la República Dominicana. Kearney, NB: s.n., 2002. Quisqueya la Bella: The Dominican Republic in Historical and Cultural Perspective. Amonk, NY: M.E. Sharpe, 1997.

Céspedes, Diógenes. "Presentación". La dominicanidad de Julia Álvarez. San Juan/ Santo Domingo: Editora Imago Mundi-Ediciones Librería La Trinitaria, 2002.9-11.

Cestero, Manuel Florentino. El amor en Nueva York. Nueva York: 1920.

Cocco de Filippis, Daisy. Desde la diáspora/A Diaspora Position: selección bilingüe de ensayos-A Bilingual Selection of Essays. Nueva York: Ediciones Alcance, 2003. "Prólogo". Como los crisantemos lila: Jesusa Alfau Galván de Solalinde. Obra escogida. Daisy Cocco de Filippis, ed. Nueva York: Ediciones Alcance, 2000. 9-12.

Conway, Dennis. "Transnationalism and Return: 'Home' as an Enduring Fixture and 'Anchor."' The Experience of Return Migration: Caribbean Perspectives. Robert

Revista Iberoamericana, Vol. LXXIX, Núm. 243,
ISSN 0034-9631 (Impreso) 
P. Potter, Dennis Conway y John Phillips, eds. Alderstrut and Burlington: Asgate, 2005. 263-81.

Cruz, Angie. Soledad. Nueva York: Simon \& Schuster, 2001.

Let it Rain Coffee. Nueva York: Simon \& Schuster, 2005.

Di Pietro, Giovanni. La dominicanidad de Julia Álvarez. San Juan/Santo Domingo: Editora Imago Mundi-Ediciones Librería La Trinitaria, 2002.

Díaz, Junot. Drown. New York: Riverhead Books, 1996.

The Brief Wondrous Life of Oscar Wao. New York: Riverhead Books, 2007.

Díaz-Quiñones, Arcadio. Sobre los principios: los intelectuales caribeños y la tradición. Bernal: Universidad Nacional de Quilmes, 2006.

Espaillat, Rhina P. Agua de dos ríos. Poemas, prosas y traducciones: una selección bilingüe. Santo Domingo: Editora Nacional, 2006.

Fernández-Alfaro, Berta, y Gerard Pascua. "Migration Management Challenges in the Caribbean." Intra-Caribbean Migration and the Conflict Nexus. Taryn Lesser, Lancelot Cowie y Nina Bruni, eds. Ottawa: Human Rights Internet, 2006. 70-87.

Garrett, Ashley, y Amy Mahoney. "Scope and Nature of the Trafficking Phenomenon: A Regional Perspective." Intra-Caribbean Migration and the Conflict Nexus. Taryn Lesser, Lancelot Cowie y Nina Bruni, eds. Ottawa: Human Rights Internet, 2006. 147-66.

Glick-Schiller, Ninna, Linda Basch y Cristina Blanc-Szanton, eds. Towards a Transnational Perspective on Migration: Race, Class, Ethnicity, and Nationalism Reconsidered. Vol. 45. Nueva York: The Annals of the New York Academy of Sciences, 1992.

Gowricharn, Ruben S., ed. Caribbean Transnationalism: Migration, Pluralization, and Social Cohesion. Lanham: Lexington Books, 2006.

Gutiérrez, Franklin. Palabras de ida y vuelta: Ensayos literarios. Nueva York: Ediciones Calíope, 2002.

Henríquez Ureña, Pedro. La cultura y las letras coloniales en Santo Domingo. Buenos Aires: Biblioteca de Dialectología Hispanoamérica, 1936.

Kirchner, Bill. “An Original and Intelligent Arranger.” The Last Post. Oct. 2001. $<$ http:// www.jazzhouse.org/lastpost2.php3?edit=1002296732\#ob1>. 4 julio 2011.

Lamarche, Ángel Rafael.Los cuentos que Nueva Yorkno sabe. México: Talleres Gráficos de la Carpeta, 1949.

Lamming, George. Coming, Coming Home: Conversations II. Philisburg, St. Martin: House of Nehesi Publishers, 2000.

Landestoy, Carmita. Yo también acuso. Nueva York: Azteca Press, 1946.

Lara, Ana Maurine. Erzulie's Skirt. Washington, DC: RedBone Press, 2006.

Marcano, José. E. "La Diáspora Dominicana". Mi País. <http://www.jmarcano.com/ mipais/cultura/emigra/emigra1.html>. 4 julio 2011.

Revista Iberoamericana, Vol. LXXIX, Núm. 243, Abril-Junio 2013,
ISSN 0034-9631 (Impreso) 
Ospina, William. Las auroras de sangre: Juan de Castellanos y el descubrimiento poético de América. Bogotá: Editorial Norma, 1999.

Pérez, Loida Maritza. Geographies of Home. Nueva York: Viking, 1999.

Rosario, Nelly. "On Becoming." Becoming American: Personal Essays by First Generation Immigrant Women. Meri Nana-Ama Danquah, ed. Nueva York: Hyperion, 2000. 156-64.

Song of the Water Saints. Nueva York: Pantheon Books, 2002.

Torres-Saillant, Silvio. "Before the Diaspora: Early Dominican Literature in the United States." Recovering the US Hispanic Literary Heritage. Vol. 3. María Herrera Sobek yVirginia Sánchez-Korrol, eds. Houston: Arte Público Press, 2000. 250-67. "Diáspora e identidad cultural". Conferencia dictada en la Fundación Global Democracia y Desarrollo. Santo Domingo, 11 sept. 2004.

Diasporic Disquisitions: Dominicanists, Transnationalism, and the Community. Working Papers Series 1. New York: The CUNY Dominican Studies Insitute, 2000. "Disquisiciones en la diáspora: Sobre dominicanistas, transnacionalismo y comunidad". Ir y venir: procesos transnacionales entre América Latina y el Norte. Sonia Báez Hernández, Anadeli Bencomo y Marc Zimmerman, eds. Patricia Gubitosi y Rocío Viegas, trads. Houston: LACASA Publications/U of Houston, 2007. 175-205.

"Formalismo y credo musical: Introducción a la poesía de Rhina P. Espaillat". Agua de dos ríos. Poemas, prosas y traducciones: una colección bilingüe. Rhina Espaillat. Santo Domingo: Editora Nacional, 2006. 2-31.

An Intellectual History of the Caribbean. New York and Houndmill: Palgrave Macmillan, 2006.

El retorno de las yolas: ensayos sobre diáspora, democracia y dominicanidad. Santo Domingo: Ediciones Librería La Trinitaria y Editora Manatí, 1999.

"Writing Has to Be Generous: An Interview with Angie Cruz." Calabash: A Journal of Caribbean Arts and Letters 2/2 (verano/otoño 2003): 108-27.

\footnotetext{
Sevista Iberoamericana, Vol. LXXIX, Núm. 243, Abril-Junio 2013, 501-522 